\title{
Yüzdeki Gizem: Karşılaşmalar, Emosyonlar ve İfadeler
}

\author{
Öz
}

Yüzler duygulanışları ne ölçüde ifade eder? Yüzlerdeki ifadeler duyguları ne ölçüde doğru temsil eder? Yüze bakarak bir bedende ne olup bittiğini saptamak ne ölçüde olanaklıdır? Bu ve benzeri sorular özellikle son elli yılda felsefe, psikoloji ve nöroloji gibi farklı disiplinleri bir arada düşünmeye zorluyor. Felsefe konuya 'uzak bir genellikten' yaklaşıyor gibi görünmekle birlikte, konunun ayrıntılarına 'spesifik bir yakınlıktan' yaklaşan diğer iki disiplinle anlamlı bir tartışma sürdürme olanağına sahip. Bu çalışma sözü edilen olanağı Spinozacı bir perspektiften araştırma amacındadır.

\section{Anahtar Kelimeler}

Yüz, Karşılaşma, Emosyon, İfade, Spinoza.

\section{The Secret in the Face: Encounters, Emotions and Expressions}

\begin{abstract}
To what extent faces are indicators of the emotions? Besides, to what extent do they truly represent our emotions? How rigorously can we predict what has really been taking place in a body just by monitoring one's face? The questions of this kind have forced such diverse disciplines as philosophy, psychology and neurology to meditate in collaboration with the each other. Though philosophy seems to approach those questions from a 'wider scope', it still has evidently a promising potential to maintain a meaningful conversation with the latter two disciplines that adapts more a 'specific focus'. This piece of work aims to disclose this possibility from a Spinozistic perspective.
\end{abstract}

\section{Keywords}

Face, Encounter, Emotion, Expression, Spinoza. 
İngilizce "emotion" sözcüğü için Türkçe'de özgül bir karşılığımız var gibi görünmüyor. Batı dillerinde kaynağında Latince "emovere" sözcügünü bulduğumuz kavram, 16. yüzyılda önce Fransızca'ya Latince ile benzer bir anlam içeriğinde, "harekete geçmek" biçiminde geçmiş, üstelik bu geçiş anlam yapısında "toplumsal bir kalkışma-hareketlenme" gibi çağrışımları da getirmiştir. İngilizce'ye 18. yüzyılda anılan Fransızca kökeninden taşınan "emotion", devinim kaynağı olan güçlü bir etkileniş ya da duygulanış anlamlarını kapsayacak biçimde genişlemiştir. Thomas Dixon, izini sürdüğü "emosyon" kavramı için, 19. yüzyıla kadar ne felsefe ne de psikoloji disiplininde araştırmacıların ortak bir anlam içeriğinde buluşabildiğini, en fazla "emotions" (emosyonlar) ile "affections" (etkilenişler/duygulanışlar) arasında bir ayrıma gitmek konusunda uzlaştıklarını yazar (bkz. Dixon 2012). Türkçe'de, sözü edilen türde bir ayrıştırmanın da olmadığı bu araştırma alanında özellikle Spinoza üzerine gelişen yazında "emosyon" sözcüğü bedenin çoklukla dışarıdan (kendi olmayanlardan) etkilenişleri, buna dayalı duygulanışları, dönüşümleri gibi anlamları da kapsayacak ölçüde heterojenleştiği dikkat çekmektedir.

Batı felsefesinde özellikle Sokrates sonrası tüm ana akımda "emosyon", büyük ölçüde "akıl" (reason) ve "ruh" (soul) ile belli bir gerilim içinde, belli bir karşıtlı içinde düşünülmüştür. Platon hem Phaedo hem de daha sonra Republic'te ruhun ölümsüzlügü ve rasyonelliği ile bedenin irrasyonelliğini önemli bir karşıtlık içinde değerlendirmiş, emosyonlar, tutkular ve bunlarla bir arada düşünülen arzu kavramını bedene ilişsin olgular arasında irdelemiştir. Platon, "beden ruhu etkilediği ölçüde onu bulanıklaştırır, hakikat ve erdeme kavuşmasına engel teşkil eder" derken dikkat çektiği büyük ölçüde bedenden türeyen emosyonlardır.

Platon'dan belli açılardan ayrılan Aristo için insan ruhu rasyonel ve irrasyonel birimlerin bir aradalığı kapsamında ele alınmalıdır. Ruhun irrasyonel biriminde iki element iş başındadır ve bunlardan insanın bir gıdayı sindiren, gelişme ve büyümesini yöneten 'bitkisel' (vegetative) elementin 'akıl' (reason) ile doğrudan bir etkileşimi yoktur. Antik terimlerle ifade edilecek olunursa, var kalma amaçlı metabolizmik itki, ruhun irrasyonel bir elementi olarak- akıldan pay almaz. Öte yandan, yine ruhun irrasyonel bir birimi olan "iştah" (appetitive) elementinin akılda bir payı vardır ve Aristo'ya göre akıl (reason) bu element üzerinde yönetsel bir güce sahip olabilir. Emosyonların tümü, arzular ve tutkular Aristo için ruhun bu biriminden türemekle birlikte adeta rasyonel ve irrasyonel birimler arasında bir bağlantı ilişkisi olarak iş görürler (1984: 29-33). Aristo için ruha ilişkin bu konfigürasyonun belirtileri insanın günlük pratik yaşamında sıklıkla "akıl" ile "duygular" arasında belirgin bir çatışma ya da gerilim biçiminde ortaya çıkar.

Buna göre, Batı rasyonalitesi bu kurucu Antik kaynaklardan beslenerek bir anlamda emosyonu akılla dengelenmesi zorunlu, aksi halde insanı irrasyonel davranmaya yöneltebilen güçlü motifler bütünü olarak değerlendirecek biçimde bir kanon oluşturmuştur. Sözgelimi "arzu", bir emosyon olarak hem Semavi dinler hem de Batı felsefesi için yoldan çıkarıcı, aşırılık kaynağı, günahın ya da yanlışın gerisindeki güçlü motifler bütünü olarak anılmak bakımından belki de en önemli uzlaşımlardan birini oluşturmuştur. Platon hemen tüm emosyonları, insanı görünüşler dünyasının geçici sözde kıymetlerine çeken derin bir yanılsamanın kaynağı olarak görmüş, hakikatin idealar katına akli bir erişim için bunlara karşı insanı uyarmayı seçmiş; Aristo 
emosyonları yok saymamış, ancak çareyi bu güçlü etkileri akılla dengelemekte bulmuş ve örneğin öfke ve korku gibi aşırılık riski taşıyanlar arasında altın denge önermiş; tüm Ortaçağ emosyonları baskılamanın türlü yollarını denemiş ve bu temkinlilik modern döneme kadar benzer bir eksende gelişmiştir.

Emosyonla ilgili olarak felsefe tarihinin belki de en gerçekçi değerlendirmesi Spinoza'dan gelir: Ona göre, duygulanışlar evrendeki diğer tüm fiziksel olgular gibi ve onlar kadar doğal, karşılaşmaların kaçınılmaz olmasına bağlı olarak zorunlu, kendi içlerinde ne iyi ne de kötü, "modus"un karşılaşmasından eyleme gücünü artıracak bir etkilenişle çıkması durumunda iyi, diğer durumda kötü olarak ifade edilmiştir. Spinoza'nın bu tutumunun gerisinde kendisinden önceki felsefe tarihinin önemli bir geleneğinin genel olarak "insan"la ilgili yaklaşımına yönelik eleştiri olduğu anlaşılır:

Hakikatte denebilir ki onlar insana, sanki Tabiattaki bir saltanat içinde başka bir saltanat gözü ile bakmışlardır: Zira onlar insanın Tabiat düzenine bağlı olmak şöyle dursun onu bozduğunu, aksiyonları (etkileri) üzerinde mutlak bir gücü olduğunu ve kendisini ancak kendi kendisiyle gerektirdiğini zannederler (Spinoza 2014: 130).

Spinoza bir emosyonla, özgül (spesifik) olarak 'o emosyonun' "varlığın eyleme gücüne ne yaptığını anlamak-kavramak" amacıyla ilgilenir; ama burada varlığı tartışmamız bağlamında insan varlığını- evrensel, zamandan bağımsız, her yerde ve her zaman "bir" ve "aynı" entite olarak değil de, her karşılaşmada karşılaşmaya bağlı ve ona göre "duygulanan" (being affected) dinamik bir varkalma çabasının adresi olarak düşünür. Dolayısıyla, Spinoza için bir emosyon, her zaman ve herkes için her seferinde eyleme gücü üzerinde benzer bir etkinin kaynağı olsa da, kimin hangi karşılaşmada hangi emosyonla etkileneceği evrensel-statik bir olgu olarak ortaya çıkmaz.

Spinoza için kederle duygulanış hemen her zaman varlığın eyleme gücünü azaltır, sevinçle duygulanışsa hemen her zaman artırır. Spinoza bu duygulanışların tanımlarını şöyle yapar: "Sevinç insanın daha az bir yetkinlikten daha büyük bir yetkinliğe geçişidir" ve "Keder, insanın daha büyük bir yetkinlikten daha az bir yetkinliğe geçişidir." (2014: 181). Bu iki duygulanışın bu sonuçları üretmesi tümüyle, bir diğer ve temel duygulanış olan "arzu" nedeniyledir. Arzu, bir anlamda her varlığın olduğu kadar insan 'modus'unun da özü sayılan 'conatus'un -var kalma çabası- doğrudan bir ifadesidir.

Öyleyse, Spinoza'ya göre, bir karşılaşma bir modus için örneğin "öfke" emosyonunun kaynağı olabilecekken, bir başka modus için öyle olmayabilir. Spinoza'da bir emosyonun etkisi tüm moduslar için benzer olabilse de, hangi karşılaşmanın karşılaşmanın taraflarında hangi emosyonu türetebileceği tümüyle belirsizdir. $\mathrm{Bu}$ belirsizlik, bir modus'un bir karşılaşmadan eyleme gücünü artıracak bir emosyon devşirebilmeyi "öğrendiği" ölçüde aşılabilir. (Doğa/Tanrı'yı upuygun kavradığı ölçüde de denebilir.) Spinoza bu konuyu Etika üçüncü kitabın daha ilk önermesinde açar: "Ruhumuz bazı şeylerde etkindir, bazı şeylerde edilgindir (tesir eder ya da tesir alır); yani upuygun fikirleri olduğu zaman zorunlu olarak etkindir, fikirleri upuygun değil olduğu zamansa zorunlu olarak edilgindir." (Spinoza 2014: 131).

19. yüzyılda Darwin sahneye çıtığında emosyonlar tartışmasının seyrinde önemli bir değişme olur: Artık konu daha çok bir emosyonun insandaki dişa vurumunun 
ya da ifadesinin ne ölçüde saptanabileceği, bunun ne ölçüde evrensel bir ortaklık içerdiği ve eğer içeriyorsa bunun nesnel yöntemlerle nasıl saptanacağı olmuştur.

Darwin araştırmaları sonucunda bütün insanların, yaş, cinsiyet ve ırk farkı olmaksızın emosyonları aynı biçimlerde ifade ettiğini ileri sürdü. Onun ilgisinin gerisinde aslen, insanlar ve hayvanlar arasındaki evrimsel sürekliliğin bir kanıtı sayılmak üzere emosyonların türsel bir ortak ifadenin konusu olduğunu göstermek vardı. 19. yüzyıldaki teolojik argümanların temelinde Tanrısal maksatlı bir yaratımın ayrıcalıklı eseri olan insanın biricikliği savının yattığını bilen Darwin, emosyonlar tartışmasında da hayvandan insana evrimsel bir süreklilik olduğu karşı argümanını benimsemiş, dolayısıyla emosyonların evrensel ortak ifadelerini derlemek yoluna gitmişti.

Öte yandan, Darwin'in bir anlamda insanı ilahi bir yaratımın konusu yaparak diğer tüm varlıklardan ayıran ve onu "eşref-i mahluk" sayan teolojik argümanların önünü kesmek için gösterdiği bu çaba, yakından bakıldığında ironik olarak Darwinci evrimsel adaptasyon düşüncesiyle çelişen bir strateji ortaya koyuyordu. Tüm insanlarda, hatta hayvanlarda da emosyonların temel olarak aynı ifadelere/dişavurumlara sahip olduğunu ileri sürmek, en azından "emosyonların ifadelerini" çevresel adaptasyonun, karşılaşmaların ve buna dayalı öğrenmenin sonucu olacağı fikrini dışlıyordu. ${ }^{2}$

Çağdaş literatürde aynı tartışmayı Darwinci öngörüyü çok sayıda kanıtla buluşturan Ekman sürdürdü. Yaklaşık yarım asır boyunca, farklı ırk, kültür, cinsiyet ve yaşlarda örneklemler üzerinden sürdürdüğü çalışmalarda Ekman bir ölçüde Darwin'i onayladı: İnsanlar evrensel olarak kendilerine gösterilen farklı yüz ifadelerini tutarlı olarak aynı emosyonlarla ilişkilendiriyordu (bkz. Ekman 1992: 34-38; Ekman \& Friesen 1992: 49-98). Buna göre, sözgelimi, farklı kimlik değişkenlerine sahip binlerce örneklem, belli bir yüz ifadesinin sevinç emosyonunu dışa vurduğunu, bir başkasının öfke emosyonunu dışa vurduğunu yüksek bir korelasyonla anlayabiliyordu.

Ekman'ın çalışmalarıyla ilk ilgilenenler tahmin edileceği üzerine devletlerin gizli servisleri ve emniyet birimleri oldu: Bazı durumlarda yanılabilse bile, Ekman çalışmaları giderek yüzleri okuma bilimine dönüşmekteydi ve bu olası suçların engellenmesi ya da suçluların deşifrasyonu açılarından gayet pratik bir faydaya tahvil edilebilirdi. Ekman izleyen çalışmaları için bu tür devlet birimlerinden önemli fonlar da aldı ve çalışmaları kriminoloji laboratuvarlarına kuramsal önemli destekler sağladı, sağlamaya devam etmektedir.

Ne var ki, son 20 yılda Ekman'ın hemen herkesçe kabul gören araştırmalarına genç bir kadın araştırmacıdan itiraz geldi. Northeastern Üniversitesi'nden Psikoloji profesörü Lisa Barrett, insanların emosyonları evrensel bir tutarlılıkla ne ifade ettiğini ne de okuyabildiğini ileri sürdü. Ona göre, üstelik, emosyonların beyinde kendilerine ait bir yeri olmas1, bedende ya da yüzde de ortak bir "pattern"den (örüntü) söz edilebilmesini olanaklı kılan bir kanıt yoktu (bkz. Barrett 2006). 
Barrett'in itirazının temelinde Ekman'ın araştırmalarında sürekli tekrar eden bir yöntem zayıflığı vardı: Ekman ve takipçileri, bir anlamda, belli sayıda sepeti belli emosyon adlarıyla etiketliyor, deneklere gösterilen çok sayıda yüzü kendilerine en uygun görünen sepete atmalarını istiyordu. Oysa, Barrett, deneklere sepetler verilmeden yüzler verilip de bu yüzlerin etkisi altında olduğu emosyonları tarif edin denilince, Ekman'da korku sepetinde bulunması garanti olacak pek çok yüz kaygı, endişe, hüzün ya da benzeri başka kavramlarla tanımlanıyordu.

Bir popüler bilim yazarı şöyle diyor:

Barrett'in dikkat çektikleri semantik bir ayrımdan fazlası değil gibi görünebilir. Ama öyle değil. Barrett'in sürmekte olan tartışmalara getirdiği itiraz, emosyon çalışmalarının yönünü tümüyle değiştirebilir; çünkü eğer Barrett haklıysa ruhsal hastalıkları nasıl yorumladığımız, zihni ve benliği nasıl anladığımız, hatta bir bütün olarak Psikoloji 21. yüzyılda köklü değişikliklere uğrayabilir ( $b k z$. Fischer 2013).

Ilık bir kış günü babamla bir kaplıcanın bahçesinde ağaç altına oturmuş muhabbet ettiğimizi anımsıyorum. Beş yaşıma kadar gittiğini düşündüğüm bu anının doğduğu o mekanda babamı kaplıcada banyo aldıktan sonra iyice dinlenmiş ve oğluyla söyleşmeye can atar bir dinginlikte anımsıyorum. Çenem düşmüş ve ona çizgi romanlardan öğrendiğim maceraları sanki arkadaşlarımla birlikte benim yaşadığımı ima edecek biçimde, çocukça türlü uydurmalar, abartılar ve gülünç ayrıntılarla anlatıyor, ondan da destekleyici mimikler bekliyordum. Babam aniden o talihsiz yüzleştirmeyi yaptı: "Yavrum, çok konuşan çok yalan söyler...!" Bunu duymamla birlikte yüzüme kan hücum etmiş, kıpkırmızı kesilmiş, babamın yalnızca uydurduğumu değil, 'çok yalan söylemeye eğilimli olduğumu' da söylediğini düşünerek yıkılmıştım. Üstelik yüzümdeki kırmızılık bir türlü geçmemiş, babam bunu kolaylıkla okumuş, belli ettiğini de saklamadan üstüme gelmeyi sürdürmüştü. $\mathrm{Bu}$ yaşantının üstünden zaman geçtikçe, yüzümün yalan söylemekle hiç ilgisinin olmadığı durumlarda da önü alınmaz bir kesinlikle kızarmaya başladığını fark ettim. Bu açıkça eyleme gücümü olumsuz etkiliyor, karşılaşmanın kendisiyle ilişkilendirelemeyecek bir biçimde yüzüm yerli yersiz kızarıyordu. Bu sorunun gerisinde bir emosyan varsa, hangisiydi?

Ekmancı bir yalan makinesi karşısında olmak istemezdim. Yalan söylersem yakalanırım diye değil, söylemesem de yalancı sanılırım diye..

Bernini'nin Azize Terasa yontusundaki o yüz ifadesi hangi emosyonun dişa vurumudur? Azize Teresa (1515-1582), Hristiyanlık inancı kapsamında Tanrı aşkıyla esrimiş bir azize olarak simgeleşir. Terasa'nın kendi günlüklerinde o deneyimi şöyle ifade ettiği bilinir: "O'nun [Yüce varlığın] elinde altın bir mızrak gördüm... Onu bir kaç kez kalbimin içine saladı, mızrak iç organlarımı deşti... Acı o denli güçlüydü ki defalarca inledim, ama yine de bu acı öyle çekiciydi ki insan sonlanmasını isteyemiyordu." (Peers 1927: 197).Bernini'nin ünlü yontusunda hedefi Teresa'nın kendi günlüklerinde anlattığı esrik-ilahi bir deneyimi cisimselleştirmek, adeta Teresa'nın deneyiminin yüze vuran ifadesini aslına en yakın bir yontuyla kalıcılaştırmaktır. 
Ne var ki, yontudaki yüz ifadesi kuşkuya az yer bırakacak ölçüde açık bir "cinsel esrime" dışa vurumunu, bununla birlikte "acı" dışa vurumunu da andırmaktadır. ${ }^{3} \mathrm{Bu}$ tuhaflık konumuz açısından önemlidir, çünkü karşılaşmalarımız ve bundan tetiklenen deneyimlerimizin bizde hangi emosyonları türeteceği kadar, bu emosyonların yüzümüzde nasıl bir ifadeye dönüşeceği "doğrusal-evrensel bir statiklik"ten ziyade, "karşılaşma-[anlamlandırma]-[emosyon]-yüzsel ifade" ilişkisine bağlı olarak son derece adaptif bir dinamizm sergiler gibi görünmektedir. Bu ilişkide ilk sıranın "karşılaşma" olması, hem Spinozacı metafizik hem de nörofizyoloji açısından doğaldır: Her deneyim, deneyimin tüm tarafları açısından bir karşılaşmadır. Buna göre, yüksek sesle konuşan birinin sözlerini işitmek, bir metni -ve bu metin üzerindeki mürekkep izlerinden oluşan yazıyı- okumak, bir çiçeği koklamak ya da bir ağacın meyvesini yemek bir modus'un karşılaşmalarındandır. Bir karşılaşmanın "deneyim"e dönüşümü kimi durumlarda doğrudan ve ham olabilirken, pek çok başka durumda karşılaşmayı eş zamanlı izleyen bir "anlamlandırma"yı üretir. Böylece, "her bir karşılaşma modus'un deneyime dönüşür" dediğimizde 'karşılaşma' ve 'anlamlandırma' arasındaki bu ardışıklığı ifade etmek isteriz.

Nörolojinin meşru araştırma alanı muhtemelen soldan üçüncü ayraç ve sonraki aşama, yani 'emosyon' ve 'yüzdeki ifade' arasındaki ilişkidir; öte yandan, karşılaşmalarla başlayan bu sürecin, yüzdeki ifadede son bulan her bir tekil örneğinde [anlamlandırma] aşamasının adaptif, plastik, yani yeniden biçimlendirilebilmeye elverişli olduğunu düşünmemek için elimizde iyi nedenler var gibi görünmemektedir. Spinoza Etika elli birinci önermede şöyle yazar: "Türlü insanlar tek ve aynı objeden [buna 'karşılaşma' da denebilir] türlü tarzlarda duygulanabilirler ve tek ve aynı kimse tek ve aynı objeden türlü zamanlarda türlü tarzlarda duygulanabilir." (Spinoza 2014: 168-169). Spinoza'y1 doğrular nitelikteki güncel sinirbilim çalışmalarında beynin karşılaşmalar ve bunlardan türeyen anlamlandırma deneyimlerine bağlı olarak dinamik dönüşebilirliğine "deneyim bağımlı nöro-plastisite" denmektedir. $\mathrm{Bu}$ alandaki güncel çalışmaların birinde vurgulandığı gibi, insan beyninin yapısal esnekliği daha önceleri düşünüldüğü gibi gelişimin kimi erken ve kilit dönemlerine özgü değildir; beynin karşılaşmalar ve bunlardan türeyen deneyimlerine bağlı olarak yeni nöronal bağlar oluşturması yaşam boyu süren bir nitelik göstermektedir. Arne May'in vurguladığı gibi, "Deneysel müdahalenin farklı aşamalarında toplanan verilerin görüntülemeye dayalı olarak değerlendirildiği uzun takipli araştırmalar, öğrenmeyle ilişkili dinamik unsurların yol açtı̆̆ plastik değişiklikleri açıklama potansiyeline sahiptir." (May 2011: 447).

Yanınızda aniden ve beklenmedik bir anda patlayan bir balon sizde muhtemelen "korku" emosyonu uyandırır. Arka arkaya patlatılan balonlar olduğunda artık bu karşılaşma aynı emosyona yol açmayacaktır. Bu, Spinoza'yı haklı çıkarır: Karşılaşmalarımızın "etkileri"yle yetinmeyip, nedenlerin bilgisini çoğalttığımız ölçüde benzer karşılaşmalardan olumlu emosyonlar devşirebiliriz. Nitekim aynı önermenin Scolie'sinde Spinoza, kişinin önceden "kendisine korku veren şeye karş1 şimdi cesaret duyduğu" (Spinoza 2014: 169) durumların sıklığını vurgulayarak karşılaşmalarımızın hangi emosyonları türeteceğinin dönüşebilir/dönüştürülebilir olduğunu açıç̧a sezdirir. Spinoza burada Doğa/Tanrı'yı upuygun kavradıkça, olabildiğince bilgilendikçe, etkilerin

3 George Bataille'ın Erotizm adlı klasikleşmiş kitabının İngilizce baskısının kapağında Bernini'nin Teresa'nın bu deneyimini konu edinen yontusu vardır. Bkz. G. Bataille 1986. 
kuşatmasında çatlaklar yaratacak ölçüde nedenlerin bilgisine sirayet ettikçe, belki duygulanışın ortadan kalkmayacağını ama o duygulanışın üzerimizdeki etkisinin farklılaşacağını söyler: "İyi ve kötünün doğru bilgisi, doğru olmak bakımından hiçbir duygulanışı azaltamaz (irca edemez), fakat yalnız onu, bir duygulanış gibi göz önüne alınması bakımından azaltabilir." (Spinoza 2014: 209). İşte bu nedenledir ki, Doğa/Tanrı'nın, ya da daha çağdaş sözcüklerle söylenirse gerçekliğin olabildiğince etkin, nesnel ve şu ya da bu biçimde otoriter bir korkunun etkisinden sıyrılacak ölçüde önyargısızca araştırılması, soruşturulması ve -umud edilir ki- giderek daha az yanılgılı bilinmesi insanın karşılaşmalardan sevinçli duygulanışlar ile çıkmasına olanak verecektir. Spinozanın anımsattığı gibi, insan için üstün iyi Doğa/Tanrı'nın upuygun bilgisidir ve "erdem" sayılmaya en güçlü aday da bu tür bir kavrayışı fark etmektir.

Yüzümüzdeki ifadeler ve mimikleri olanaklı kılan nörofizyolojik süreçlerin neler olduğunun ve bunların emosyonlarla ilişkisinin anlaşılması kuşkusuz önemlidir. Ben yine de, Spinoza'ya kulak vermenin çok daha önemli olduğunu düşünenlerdenim: Karşılaşmalarımızdan hangi emosyonları türetebileceğimizi daha iyi kavramak için yapacaklarımız nelerdir?

\section{KAYNAKÇA}

ARISTOTLE (1984). "Eudemian Ethics", trans. by J. Solomon, The Complete Works of Aristotle, ed. by Jonathan Barnes, Princeton: Princeton University Press.

BARRETT, L. (2006). “Are Emotions Natural Kind?”, Perspectives on Psychological Science, 1(1)/2006: 28-58.

BATAILLE, G. (1986). Erotism: Death and Sensuality, trans. by Mary Dalwood, San Francessco: City Lights.

DARWIN, C. (1872/1998). The Expression of Emotion in Man and Animals, New York: Oxford University Press.

DIXON, T. (2003) From Passions to Emotions: The Creation of a Secular Psychological Category, Cambridge University Press.

DIXON, T. (2012). "Emotion: The History of a Keyword in Crisis", Emotion Review, 4(4)/2012: 338-344.

EKMAN, P. (1992). "Facial Expressions of Emotion: New Findings, New Questions”, Psychological Science, 3(1)/1992: 34-38.

EKMAN, P. \& W. V. FRIESEN (1969). "The Repertoire of Nonverbal Behavior: Categories, Origins, Usage, and Coding”, Semiotica, 1/1969: 49-98.

FISCHER S. (2013). "About Face: Emotions and Facial Expressions may not be Related”, Boston Magazine WEB Site [http://www.bostonmagazine.com/news/2013/06/25/emotions-facialexpressions-not-related/], 2013, Erişim Tarihi: 10.12.2017.

FREVERT, U. et. al (2014). Emotional Lexicons: Continuity and Change in the Vocabulary of Feeling 1700-2000, Oxford University Press.

MAY, A. (2011). "Experience-Dependent Structural Plasticity in the Adult Human Brain”, Trends in Cognitive Sciences, 15(10)/2011.

PEERS, E. Allison (1927). Studies of the Spanish Mystics, London: Macmillan. 
Publishing.

PLATO (1997). Complete Works, ed. J. M. Cooper \& D. S. Hutchinson, Hackett SPINOZA (2014). Etika, çev. Hilmi Ziya Ülken, Ankara: Dost Yayınları. 